\title{
Spatial and seasonal patterns in acoustic detections of sperm whales Physeter macrocephalus along the continental slope in the western North Atlantic Ocean
}

\author{
Joy E. Stanistreet ${ }^{1, *}$, Douglas P. Nowacek ${ }^{1,2}$, Joel T. Bell ${ }^{3}$, Danielle M. Cholewiak ${ }^{4}$, \\ John A. Hildebrand ${ }^{5}$, Lynne E. W. Hodge ${ }^{1}$, Sofie M. Van Parijs ${ }^{4}$, Andrew J. Read $^{1}$ \\ ${ }^{1}$ Duke University Marine Laboratory, Nicholas School of the Environment, Beaufort, North Carolina 28516, USA \\ ${ }^{2}$ Pratt School of Engineering, Duke University, Durham, North Carolina 27708, USA \\ ${ }^{3}$ Naval Facilities Engineering Command Atlantic, Norfolk, Virginia 23508, USA \\ ${ }^{4}$ Northeast Fisheries Science Center, Woods Hole, Massachusetts 02543, USA \\ ${ }^{5}$ Scripps Institution of Oceanography, University of California San Diego, La Jolla, California 92093, USA
}

\begin{abstract}
The distribution and seasonal movements of sperm whales Physeter macrocephalus are poorly understood in the western North Atlantic Ocean, despite a long history of human exploitation of the species. Cetacean surveys in this region are typically conducted during the summer, when weather conditions are amenable for visual observation, resulting in a seasonal bias in species occurrence data. In the present study, we conducted multi-year passive acoustic monitoring to assess year-round sperm whale occurrence along the continental slope between Florida and New England, USA. Between 2011 and 2015, we collected 2037 d of recordings using bottom-mounted recorders deployed at 5 sites. We analyzed these recordings for sperm whale echolocation clicks, which were detected commonly between New England and North Carolina, but infrequently off the coast of Florida. In the northern half of the study region, we observed distinct seasonal patterns in the daily prevalence of sperm whale clicks, with a winter peak in occurrence off Cape Hatteras, North Carolina, followed by an increase later in the spring at sites further north. South of Cape Hatteras, seasonal patterns were less apparent. We detected sperm whale clicks during all hours of the day throughout the study area, and did not observe strong diel patterns. Overall, our results provide a comprehensive year-round baseline on the occurrence of sperm whales across multiple recording sites, demonstrating the utility of passive acoustic monitoring to assess patterns in sperm whale occurrence across broad spatial and temporal scales.
\end{abstract}

KEY WORDS: Sperm whale $\cdot$ Physeter macrocephalus $\cdot$ Passive acoustic monitoring $\cdot$ Seasonality Distribution · North Atlantic Ocean

\section{INTRODUCTION}

The seasonal distributions of many pelagic cetacean species are poorly known, owing to their highly mobile lifestyle and the vast extent of their oceanic habitat, which makes habitat-scale observations exceedingly difficult. Shipboard and aerial

*Corresponding author: joy.stanistreet@duke.edu surveys for cetaceans are typically costly, laborintensive, and dependent on weather conditions, and these practical limitations create a tradeoff between surveying broad spatial areas and obtaining repeated observations over time within the same region. Consequently, assessing spatiotemporal patterns in cetacean occurrence remains a chal-

(C) The authors 2018. Open Access under Creative Commons by Attribution Licence. Use, distribution and reproduction are unrestricted. Authors and original publication must be credited. 
lenge, especially for species that range across ocean basins.

Sperm whales Physeter macrocephalus are among the most widely distributed mammalian species on earth, found throughout the world's oceans from the equator to the polar ice edges (Rice 1989), with individual home ranges that can span more than $1000 \mathrm{~km}$ in diameter (Whitehead 2003). The global distribution of this species has held particular significance to humans for nearly 3 centuries, as sperm whales were an important target for the whaling industry in the $18^{\text {th }}$ and $19^{\text {th }}$ centuries, beginning in the Atlantic Ocean and later expanding throughout the world. Sperm whales were targeted again by modern whalers in the mid- $20^{\text {th }}$ century, with catch rates peaking in the $1960 \mathrm{~s}$ prior to an international moratorium on commercial whaling which took effect in 1985 (Best 1983). Whitehead (2002) estimated that the global abundance of sperm whales was reduced to $30 \%$ of their pre-whaling numbers as a result of human exploitation.

Charts compiled from whaling logbooks provide some of the earliest information on the spatial and temporal distributions of sperm whales, and document the presence of 'grounds' or areas of relatively high density in each ocean basin (Townsend 1935). In the western North Atlantic, sperm whales were hunted off the entire east coast of the USA, with a particular emphasis on the 'Charleston Ground' located southeast of Cape Hatteras, North Carolina and some historical references to the 'Hatteras Ground,' located closer to the cape (Goode 1884, Townsend 1935, Smith et al. 2012). Concentrations of sperm whales were observed east of the US coast between Cape Hatteras and the Bahamas, particularly between February and May (Tomilin 1957). Today, sperm whales inhabiting the western North Atlantic are mainly encountered along the edge of the continental shelf and offshore, particularly near submarine canyons and seamounts (Waring et al. 2001, Wong \& Whitehead 2014). A seasonal latitudinal shift in sperm whale densities has been suggested to occur in this region, with greater concentrations found east and northeast of Cape Hatteras during the winter months, followed by a northward expansion to the shelf break along the mid-Atlantic Bight, Georges Bank, and southern New England during the spring and summer (Perry et al. 1999, Waring et al. 2014). A recent effort to create spatially and temporally explicit models of sperm whale density throughout the US east coast region by Roberts et al. (2016a) provided support for this pattern, but the authors noted that survey data from non-summer periods were scarce, limiting their ability to effec- tively model seasonal changes (see also Roberts et al. 2016b). Most information on sperm whale occurrence and abundance in US waters in the past few decades has come from dedicated shipboard and aerial visual surveys conducted over the continental shelf and along the shelf break and slope regions during spring and summer months, when weather conditions are most favorable for visual observation.

To overcome this seasonal bias in cetacean occurrence data, passive acoustic monitoring is increasingly being used to obtain continuous records of species presence throughout the year, especially in remote offshore regions that are difficult to access, particularly during the winter. Recently, broad-scale passive acoustic monitoring with fixed recorders has been effectively used to describe seasonal migration patterns of baleen whale species (Risch et al. 2014, Thomisch et al. 2016) as well as spatiotemporal distributions of odontocetes, such as beaked whales, at locations distributed across an ocean basin (Baumann-Pickering et al. 2014).

Sperm whales are highly vocal, producing several types of impulsive broadband signals that fulfill both sensory and communicative functions. The most commonly produced sperm whale sounds are echolocation clicks, often referred to as 'regular' or 'usual' clicks. These powerful, highly directional clicks are typically produced at evenly spaced intervals of 0.2 to $2.0 \mathrm{~s}$ throughout foraging dives (Wahlberg 2002, Watwood et al. 2006), and contain energy predominantly at frequencies between 5 and $15 \mathrm{kHz}$ (Madsen et al. 2002a, Møhl et al. 2003, Zimmer et al. 2005). During foraging dives, trains of regular clicks are punctuated by 'creaks' (also called buzzes), consisting of short bursts of clicks with a higher repetition rate, which are believed to occur during prey capture attempts as the whale closes in on prey (Miller et al. 2004). Sperm whales also emit clicks associated with social behavior, including 'codas', which are patterned series of clicks most commonly recorded among female groups (Watkins \& Schevill 1977, Weilgart \& Whitehead 1993), and 'slow clicks' or 'clangs,' which are produced by mature males and characterized by lower frequency content, longer inter-click-intervals ( $>2 \mathrm{~s}$ ), and a distinctive ringing tone that makes them audibly distinct from regular clicks (Weilgart \& Whitehead 1988).

Since the first descriptions of sperm whale calls by Backus \& Schevill (1966), vessel-based acoustic surveys have played an important role in the study of this species. Real-time passive acoustic monitoring allows researchers to detect and track vocalizing animals during the long periods when they are not visi- 
ble at the surface, thus providing a window into foraging behaviors and social interactions. Despite longstanding scientific interest in the acoustic behavior of sperm whales and the widespread use of acoustic methods to assist in locating, tracking, and counting these whales (e.g. Wahlberg 2002, Barlow \& Taylor 2005), only a few published studies have employed fixed, bottom-mounted acoustic recorders to examine the seasonal presence and foraging activity of sperm whales across broad spatial scales and/or multiple seasons or years (Mellinger et al. 2004, Wong \& Whitehead 2014). In the present paper, we describe seasonal patterns in acoustic detections of sperm whales along a portion of the continental slope in the western North Atlantic Ocean. We analyzed passive acoustic recordings collected between Florida and New England to provide new baseline information on year-round sperm whale presence in this region, and to determine whether there is evidence of seasonal shifts in the relative occurrence of sperm whales across recording sites.

\section{MATERIALS AND METHODS}

\section{Data collection}

We collected passive acoustic recordings at 5 sites along the continental slope in the western North Atlantic Ocean between August 2011 and May 2015 (Fig. 1, Table 1). All recording sites were located at depths between 800 and $970 \mathrm{~m}$. Temporal coverage varied among sites, due to evolving data collection objectives and occasional instrument failures that

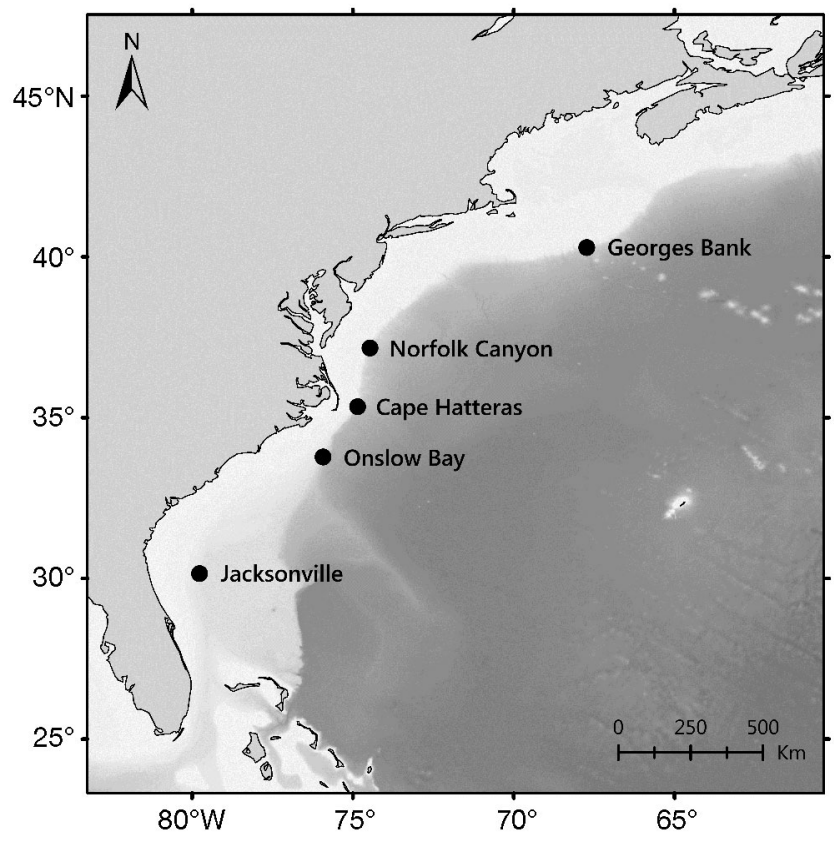

Fig. 1. Passive acoustic recording sites off the east coast of North America in the western North Atlantic Ocean

occurred over the course of the study. The total recording effort consisted of a single 10-mo deployment at each of the Georges Bank, Norfolk Canyon, and Jacksonville sites, and multiple deployments conducted across 2 to $3 \mathrm{yr}$ at the Cape Hatteras and Onslow Bay sites (Table 1). We used 2 types of autonomous, bottom-mounted recording devices to collect passive acoustic recordings: High-frequency Acoustic Recording Packages (HARPs; Wiggins \& Hildebrand 2007) and an Autonomous Multi-channel Acoustic Recorder (AMAR; JASCO Applied Sci-

Table 1. Summary of passive acoustic monitoring effort in the western North Atlantic Ocean between 2011 and 2015. Instrument type specifies either an Autonomous Multi-channel Acoustic Recorder (AMAR) or High-frequency Acoustic Recording Package (HARP). Duty cycles are defined as the duration of the recording period/cycle period, with cycle period specifying the interval between the start of one recording period and the start of the next. Dates are given as mo/d/yr

\begin{tabular}{|c|c|c|c|c|c|c|c|}
\hline Site & Location & $\begin{array}{l}\text { Depth } \\
\text { (m) }\end{array}$ & $\begin{array}{l}\text { Recording } \\
\text { dates }\end{array}$ & $\begin{array}{l}\text { No. of } \\
\text { recording days }\end{array}$ & $\begin{array}{l}\text { Instrument } \\
\text { type }\end{array}$ & $\begin{array}{l}\text { Duty cycle } \\
\text { (mm:ss) }\end{array}$ & $\begin{array}{l}\text { Sampling } \\
\text { rate }(\mathrm{kHz})\end{array}$ \\
\hline Georges Bank (GBK) & $40.29^{\circ} \mathrm{N}, 67.72^{\circ} \mathrm{W}$ & 800 & $7 / 27 / 14-5 / 26 / 15$ & 304 & AMAR & $2: 40 / 30: 00$ & 250 \\
\hline Norfolk Canyon (NFC) & $37.16^{\circ} \mathrm{N}, 74.47^{\circ} \mathrm{W}$ & 980 & $6 / 20 / 14-4 / 4 / 15$ & 289 & HARP & Continuous & 200 \\
\hline Cape Hatteras (HAT) & $35.34^{\circ} \mathrm{N}, 74.85^{\circ} \mathrm{W}$ & $\begin{array}{l}950 \\
970 \\
970 \\
850\end{array}$ & $\begin{array}{c}3 / 16 / 12-4 / 10 / 12 \\
10 / 10 / 12-4 / 30 / 13 \\
5 / 30 / 13-3 / 14 / 14 \\
5 / 9 / 14-12 / 10 / 14\end{array}$ & 734 & HARP & Continuous & 200 \\
\hline Onslow Bay (ONB) & $33.78^{\circ} \mathrm{N}, 75.93^{\circ} \mathrm{W}$ & $\begin{array}{l}950 \\
915 \\
850\end{array}$ & $\begin{array}{c}8 / 19 / 11-11 / 30 / 11 \\
7 / 14 / 12-10 / 1 / 12 \\
10 / 25 / 12-6 / 29 / 13\end{array}$ & 432 & HARP & $5: 00 / 10: 00$ & 200 \\
\hline Jacksonville (JAX) & $30.15^{\circ} \mathrm{N}, 79.77^{\circ} \mathrm{W}$ & 806 & $8 / 24 / 14-5 / 28 / 15$ & 278 & HARP & Continuous & 200 \\
\hline
\end{tabular}


ences). HARPs were programmed to collect recordings at a sampling rate of $200 \mathrm{kHz}$, either continuously (Jacksonville, Cape Hatteras, and Norfolk Canyon sites) or on a duty-cycled schedule of $5 \mathrm{~min}$ of recording time repeating every $10 \mathrm{~min}$ (Onslow Bay site). The AMAR, deployed at the Georges Bank site, sampled at $250 \mathrm{kHz}$ on a duty cycle of 2 min and $40 \mathrm{~s}$ repeating every $30 \mathrm{~min}$. This recording schedule was used to maximize the deployment duration, given the data storage capacity of the device. After retrieval of each instrument, we analyzed all recording days that included a full $24 \mathrm{~h}$ of data, excluding the first and last day of each deployment which had only partial recording coverage.

\section{Acoustic data analysis}

We manually screened the acoustic recordings for sperm whale signals using long-term spectral aver- ages (LTSAs), which provide a compressed spectrogram view allowing efficient visual examination of long datasets (Wiggins \& Hildebrand 2007). We used the custom software program Triton (Scripps Whale Acoustic Lab, Scripps Institution of Oceanography, La Jolla, CA) developed in MATLAB (The Mathworks) to compute LTSAs with a time and frequency resolution of $5 \mathrm{~s}$ and $100 \mathrm{~Hz}$, respectively. For analysis, we viewed 0.5 to $1 \mathrm{~h}$ LTSA segments across a frequency range of 0 to $30 \mathrm{kHz}$, and marked the hourly presence or absence of sperm whale echolocation clicks, which were visible and distinguishable from background noise and signals from other species (Fig. 2A). During periods with higher background noise or many overlapping delphinid vocalizations, we verified the presence of sperm whale clicks by visually examining spectrograms (fast Fourier transform [FFT] 1024, 0.5 overlap) with a $10 \mathrm{~s}$ time window and 0 to $30 \mathrm{kHz}$ frequency range and by listening to sections of interest (Fig. 2B). In addition to regular

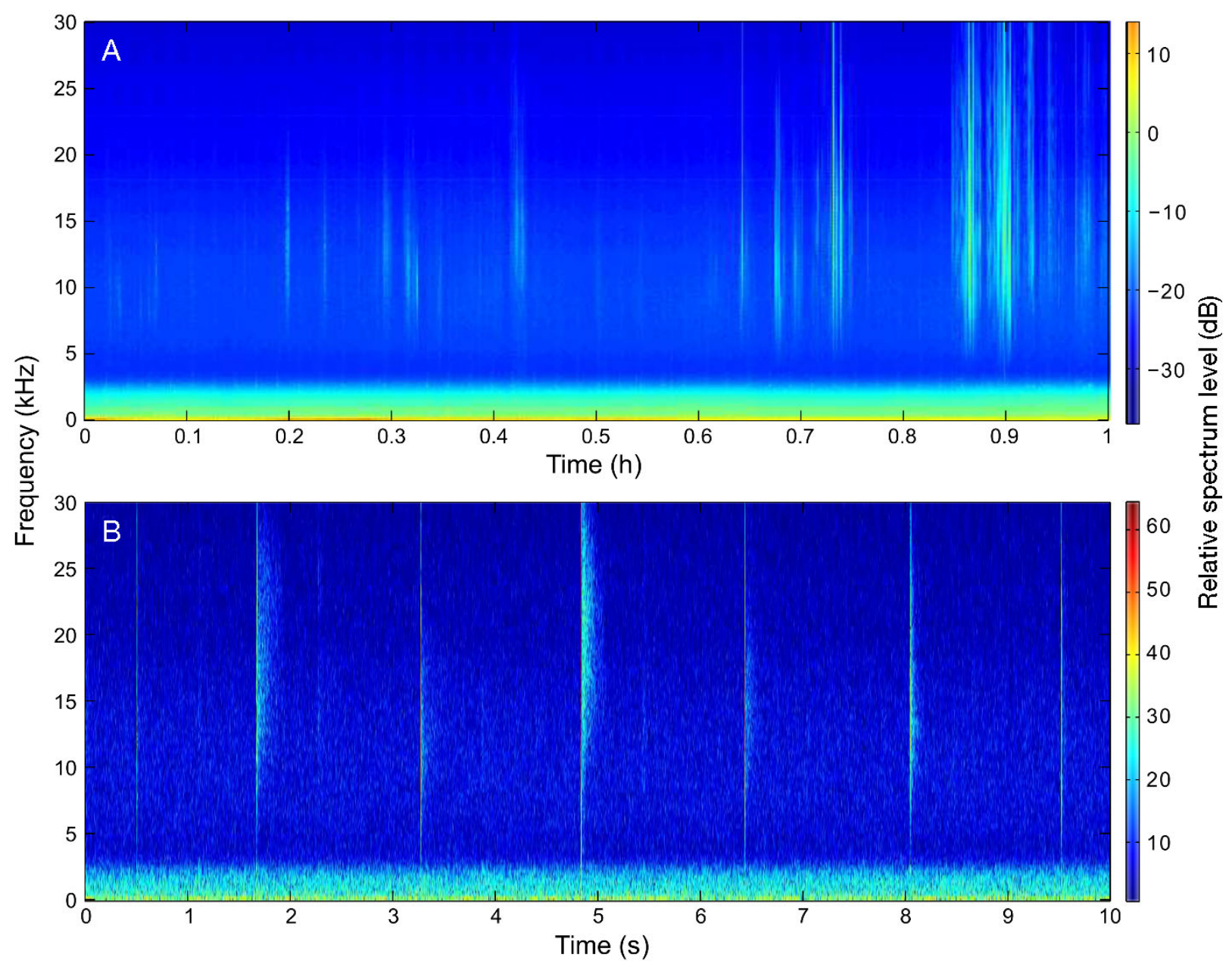

Fig. 2. Example of (A) long-term spectral average (LTSA) and (B) spectrogram containing sperm whale Physeter macrocephalus regular clicks 
(echolocation) clicks, we occasionally observed slow clicks, codas, and creaks in the recordings when viewing spectrograms; however, only regular clicks were consistently identifiable in the LTSAs. It was not feasible to review all recordings at the spectrogram level, and we therefore chose to focus solely on regular clicks, which are produced by both sexes and all age classes of sperm whales, with the exception of young calves, and thus provide a reliable indication of sperm whale presence and foraging activity (Whitehead 2003).

\section{Effects of duty-cycled recording schedules}

Recordings at the Georges Bank and Onslow Bay sites were collected using duty-cycled recording schedules, potentially leading to the underestimation of sperm whale acoustic presence. To estimate the probability of correctly assessing the hourly and daily presence of sperm whale clicks in the duty-cycled recordings, we performed a subsampling experiment using continuous HARP recordings from the Norfolk Canyon, Cape Hatteras, and Jacksonville sites. We randomly selected 100 recording days in which sperm whale signals were present, containing a total of $903 \mathrm{~h}$ with click detections, and then subsampled these data based on the 2 duty-cycled recording schedules: $5 \mathrm{~min}$ per $10 \mathrm{~min}$ cycle period or $3 \mathrm{~min}$ per 30 min cycle period, repeating continuously throughout each day. For each recording schedule we performed repeated subsampling, shifting the position of the recording period through the $10 \mathrm{~min}$ or $30 \mathrm{~min}$ cycle period in 1-min increments, and determining the presence or absence of clicks per hour and day with each subsampling permutation (10 or 30 possible permutations depending on the recording schedule). Detection probabilities for each hour and day were then calculated as the proportion of permutations which resulted in a correct assessment of presence. Finally, we calculated the mean and standard deviation of the hourly and daily detection probabilities for each recording schedule across all sampled hours and days.

\section{Statistical analysis}

To examine seasonal patterns in sperm whale acoustic presence at each recording site, we used the number of hours per day with clicks, expressed as a proportion, to compare the relative presence of foraging sperm whales across boreal seasons, defined as winter (January-March), spring (April-June), summer (July-September) and fall (October-December). For each site, we fit a binomial generalized linear model (GLM) with season as a categorical explanatory variable, and used a generalized estimating equation (GEE) approach to account for temporal autocorrelation in the model residuals (Liang \& Zeger 1986). GLMs assume independence among model residuals, but the GEE method explicitly models the correlation within specified 'blocks' of data, assuming independence between blocks, to produce robust standard errors and p-values (e.g. Panigada et al. 2008, Bailey et al. 2013, Pirotta et al. 2014). Here, we used an autoregressive (AR1) correlation structure to model the temporal dependence within blocks, since the dependence is expected to decay with time. The extent of residual autocorrelation varied among recording sites, so for each site we chose a block size of 5,20 , or $30 \mathrm{~d}$ based on examination of autocorrelation function (ACF) plots of the GLM residuals. Blocks were defined based on contiguous recording days. Seasonal recording effort varied among sites, with data available from 2 to 3 yr per season at Cape Hatteras, 1 to 2 yr per season at Onslow Bay, and a single year at Georges Bank, Norfolk Canyon, and Jacksonville. Because we lacked full seasonal coverage across replicate years of monitoring at most of the recording sites, we did not attempt to assess inter-annual variation by including an interaction between season and year. Instead, data from all years with recording effort were pooled by season within each site (Table 2). At Norfolk Canyon, only $15 \mathrm{~d}$ of recording effort took place during the spring, and we therefore omitted spring in the seasonal model for this site. We fit a separate model for each site using the 'geeglm' function in the geepack library in R (Halekoh et al. 2006), and performed post-hoc pairwise comparisons using the least-squares means ('Ismeans') function in the lsmeans library (Lenth 2016) to evaluate differences among seasons.

Table 2. Seasonal recording effort across sites, specified by the number of recording days per season at each site, pooled across all years with recordings

\begin{tabular}{|lcccc|}
\hline Site & $\begin{array}{c}\text { Winter } \\
\text { (Jan-Mar) }\end{array}$ & $\begin{array}{c}\text { Spring } \\
\text { (Apr-Jun) }\end{array}$ & $\begin{array}{c}\text { Summer } \\
\text { (Jul-Sep) }\end{array}$ & $\begin{array}{c}\text { Fall } \\
\text { (Oct-Dec) }\end{array}$ \\
\hline Georges Bank (2014-2015) & 90 & 56 & 66 & 92 \\
Norfolk Canyon (2014-2015) & 90 & 15 & 92 & 92 \\
Cape Hatteras (2012-2014) & 179 & 125 & 184 & 246 \\
Onslow Bay (2011-2013) & 90 & 90 & 122 & 130 \\
Jacksonville (2014-2015) & 90 & 58 & 38 & 92 \\
\hline
\end{tabular}


To illustrate diel patterns in sperm whale acoustic presence across time of day at each recording site, we plotted counts of hourly click presence for each hour of the day, summed across all days with click detections. To compare the relative hourly presence of clicks between day and night at each recording site, we determined local sunrise and sunset times for each calendar day with click detections, based on data from the US Naval Observatory website (http://aa.usno.navy.mil). We defined day and night diel periods as the hours between sunrise and sunset and the hours between sunset and sunrise, respectively. The hour encompassing each sunrise and sunset time was assigned to the diel period containing the majority of that hour. For each day, we calculated the number of hours with sperm whale detections as a percentage of the total number of hours in each diel period, to account for variation in the length of diel periods across latitudes and seasons. To test for differences in acoustic presence between day and night diel periods at each site, we used a nonparametric Mann-Whitney $U$-test comparing the percent of hours per diel period with clicks present. Recording dates with no sperm whale detections were omitted from this analysis.

\section{RESULTS}

We analyzed more than $48000 \mathrm{~h}$ of passive acoustic recordings collected across the 5 study sites, with the highest recording effort at the Cape Hatteras and Onslow Bay sites (Table 3). We detected sperm whale clicks at all sites, in $54 \%$ of all recording days and $16.5 \%$ of all recording hours. Evaluation of the duty-cycled recording schedules employed at Onslow Bay and Georges Bank indicated that daily presence was not substantially underestimated in the duty-cycled data, with a greater than $90 \%$ probability of correctly assessing presence (Table 4). Therefore, daily acoustic presence provided a consistent metric to compare the relative occurrence of sperm whales across recording sites, despite the use of different recording schedules. Hourly presence was substantially underestimated by the lower dutycycled recording schedule employed at Georges Bank, with a $58 \%( \pm 33 \%)$ mean probability of correctly assessing hourly presence (Table 4 ).

At the level of daily presence, sperm whales were present most frequently at Georges Bank, where
Table 4. Results of subsampling a randomly selected subset of continuous recordings to estimate the mean probability ( \pm standard deviation) of correctly assessing daily and hourly presence of sperm whale Physeter macrocephalus clicks using each duty-cycled recording schedule. Duty cycles are specified by the number of minutes of recording time/cycle

period and the percent of time recordings were made

\begin{tabular}{|llc|}
\hline & \multicolumn{2}{c|}{ Duty cycle } \\
\cline { 2 - 3 } & $5 / 10(50 \%)$ & $3 / 30(10 \%)$ \\
\hline Daily $(\mathrm{n}=100)$ & $0.99( \pm 0.07)$ & $0.92( \pm 0.20)$ \\
Hourly $(\mathrm{n}=903)$ & $0.92( \pm 0.16)$ & $0.58( \pm 0.33)$ \\
\hline
\end{tabular}

clicks were detected on $77 \%$ of recording days. Sperm whale clicks were present in 59, 65, and $49 \%$ of recording days at Norfolk Canyon, Cape Hatteras, and Onslow Bay, respectively. At Jacksonville there were notably few sperm whale detections, with clicks present on just $4 \%$ of recording days. Hourly presence followed the same trend across recording sites, but was slightly lower at Georges Bank (21\% of recording hours) than at Cape Hatteras (23\% of recording hours), likely due to substantial underestimation of hourly presence in the duty-cycled recordings collected at Georges Bank.

Sperm whale clicks were detected in all seasons of the year at each recording site, with considerable temporal variability in the number of hours per day with detections (Fig. 3). There were clear seasonal patterns in sperm whale occurrence at Georges Bank, Norfolk Canyon, and Cape Hatteras, and weaker evidence of seasonality at Onslow Bay (Figs. 3 \& 4). GEE-GLM models revealed significant effects of season on sperm whale occurrence at all sites except for Jacksonville, where there were very few sperm whale detections (for model output, see Tables S1 \& S2 in the Supplement at www.int-res. com/articles/suppl/n035p001_supp.pdf) At Georges Bank, sperm whale occurrence was significantly higher during spring than any other season, with no clear differences among winter, summer, and fall 


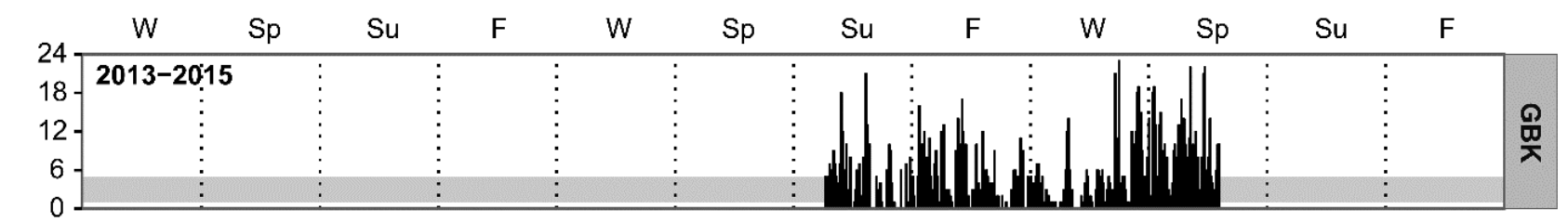
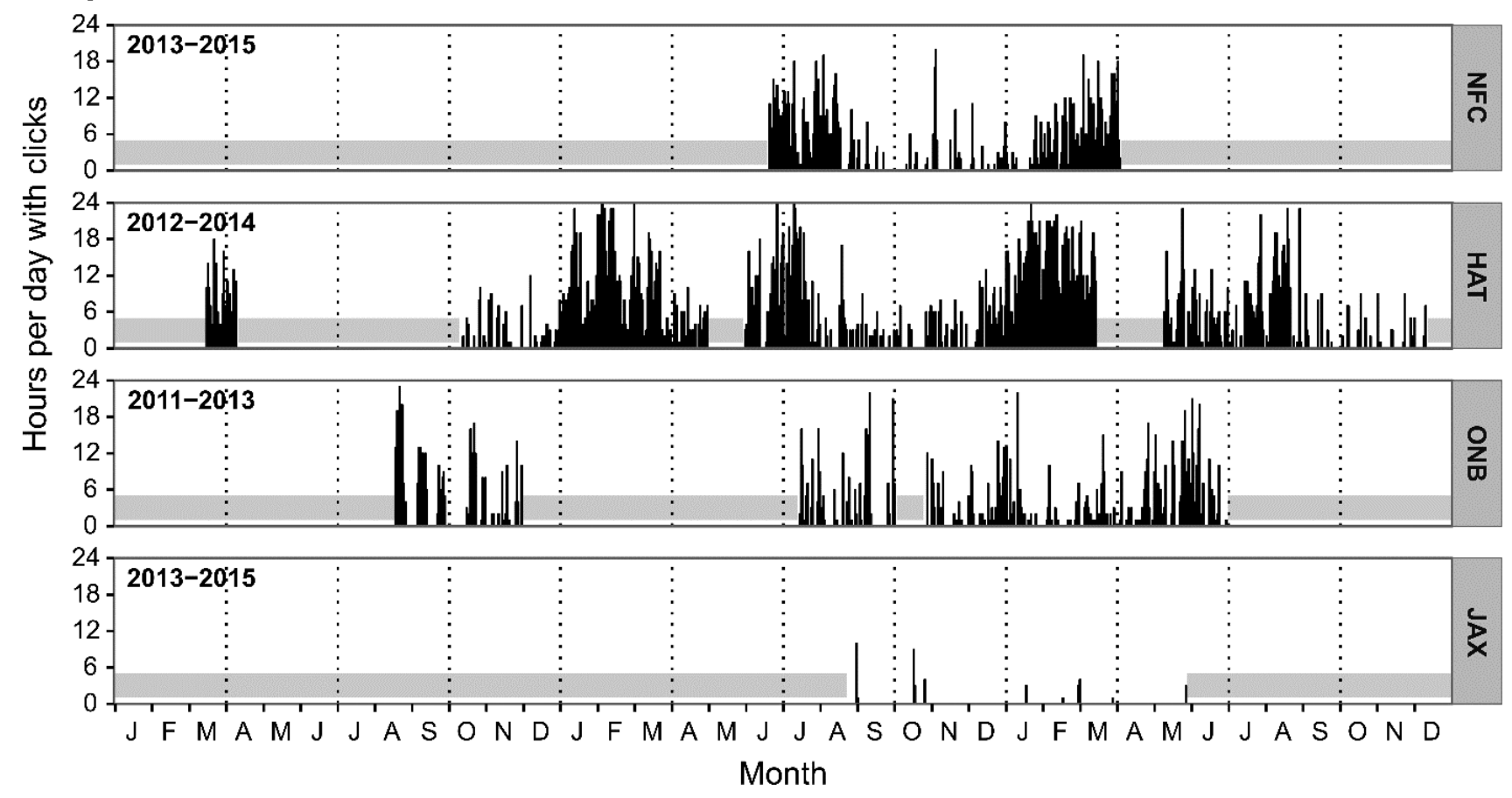

Fig. 3. Temporal occurrence of sperm whale Physeter macrocephalus regular clicks across all recording periods at the Georges Bank (GBK), Norfolk Canyon (NFC), Cape Hatteras (HAT), Onslow Bay (ONB), and Jacksonville (JAX) recording sites. Data were collected using a $10 \%$ duty-cycled recording schedule at GBK, a $50 \%$ schedule at ONB, and continuously throughout the recording periods at all other sites. Gray bars indicate periods with no recording effort. Years are specified on each panel; seasons (W: winter; Sp: spring; Su: summer; F: fall) are indicated on the top axis and delineated by dotted lines

(Fig. 4). The available data from Norfolk Canyon suggested a similar pattern at this site, but we did not include spring in our statistical comparison of seasons at this site, due to the small sample size of recording days collected during spring. We found significantly lower sperm whale occurrence in fall than either winter or summer at Norfolk Canyon (Fig. 4). Cape Hatteras exhibited the most distinct seasonal pattern of any recording site, with significantly higher sperm whale occurrence during the winter than any other season (Fig. 4). Sperm whale clicks were present at intermediate levels during the spring and summer seasons, and at consistently low levels during the fall, and this pattern was apparent across multiple years of monitoring (Fig. 3). The winter peak in sperm whale occurrence that we observed at Cape Hatteras was not present just to the south in Onslow Bay, where sperm whale click presence was higher during spring than winter, but oth- erwise not strongly seasonal (Fig. 4). At Jacksonville, sperm whale clicks were present only sporadically throughout the year, and sample sizes were too small to determine any effect of season.

Sperm whale regular clicks were recorded at all hours of the day, and we did not observe a noteworthy pattern in click presence across time of day at any recording site (Fig. 5A). Comparison of hourly presence between day and night diel periods (Fig. 5B) resulted in a significant difference only at the Georges Bank site, where the median percent of hours with clicks per diel period was greater during the day $(27 \%)$ than during the night $(18 \%)$ (MannWhitney $U$-test, $U=31706, \mathrm{p}=0.00049$ ). This result was statistically significant, but it is not clear whether this pattern has particular biological significance, because sperm whale foraging clicks were detected frequently at all hours of the day at this site, as shown in Fig. 5A. 


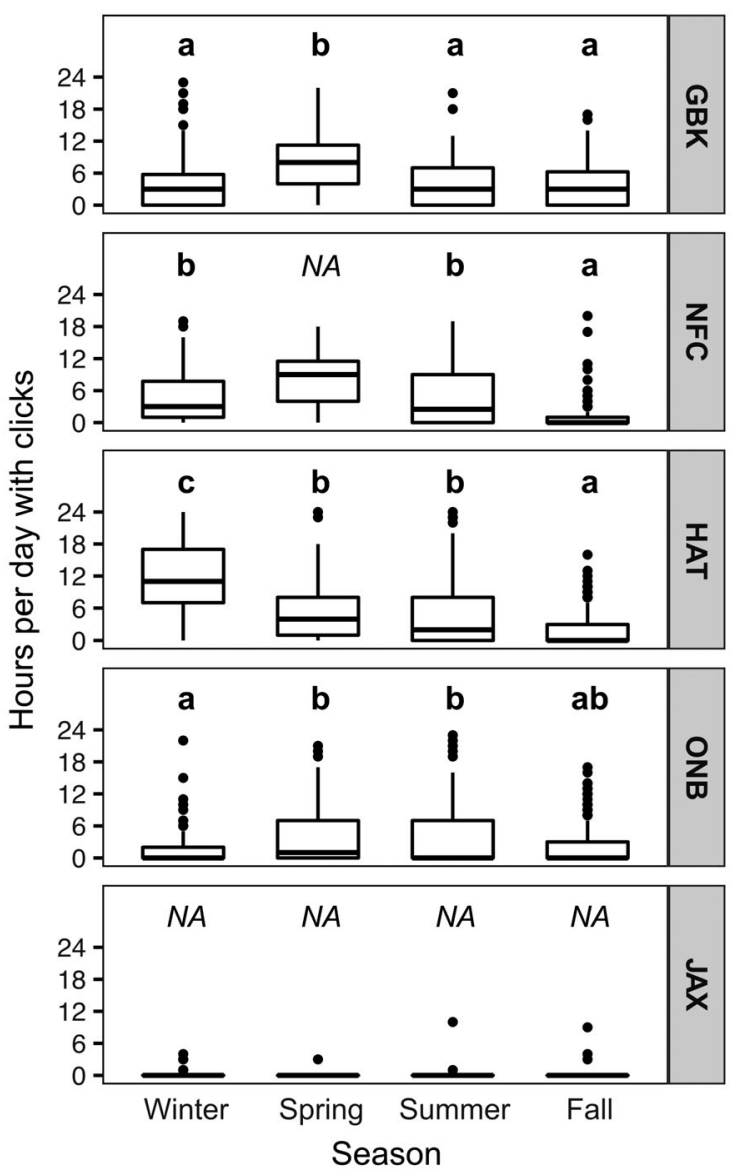

Fig. 4. Seasonal occurrence of sperm whale Physeter macrocephalus clicks at the Georges Bank (GBK), Norfolk Canyon (NFC), Cape Hatteras (HAT), Onslow Bay (ONB), and Jacksonville (JAX) recording sites, pooled across all years with recordings. Boxplots show the median and first and third quartiles, whiskers extend to 1.5 times the inter-quartile range, and points represent data beyond this range. Within each site, the proportion of hours per day with sperm whale clicks is not significantly different among seasons that share a lower-case letter; NA indicates insufficient data for statistical testing

\section{DISCUSSION}

This study represents the first broad-scale passive acoustic monitoring effort for sperm whales in the Atlantic Ocean, incorporating data from multiple sites and seasons. We detected sperm whale regular clicks year-round along the continental slope between Onslow Bay, North Carolina and Georges Bank, off southern New England, and observed both spatial and seasonal variation in relative occurrence.

Sperm whales were commonly present at all but the southernmost recording site, with the highest daily presence recorded at Georges Bank, as well as off Cape Hatteras, North Carolina. Both of these areas have been noted as seasonally important habitats for sperm whales in the western North Atlantic (Waring et al. 2014). The 'Hatteras Ground' was recognized as an important habitat for sperm whales prior to the $20^{\text {th }}$ century (Goode 1884). The Cape Hatteras slope area is characterized by a dynamic convergence of water masses that act to enhance biological productivity in the region, supporting a high density and diversity of cetacean species (Roberts et al. 2016a). In contrast to the northern portion of the study area, there were very few sperm whale clicks recorded off Jacksonville, Florida. This recording site was located on the continental slope at a comparable depth to the other sites in the study, but the bathymetry of the continental margin off the coast of Florida differs from that of the northern sites. Off Florida, the slope descends only to approximately 800 to $1000 \mathrm{~m}$ depth before flattening out into the Blake Plateau, which extends $375 \mathrm{~km}$ offshore before dropping off steeply to the abyssal plain. In contrast to the deeper slope waters further north, this area of intermediate depth over the Blake Plateau may not represent high-quality habitat for sperm whales. Density maps produced by Roberts et al. (2016b) indicate lower sperm whale abundance along the continental slope off the southeastern USA, and suggest a more offshore distribution in this region.

The seasonal patterns we observed at the Georges Bank, Norfolk Canyon, and Cape Hatteras study sites are generally consistent with the seasonal shift in sperm whale concentrations previously described in the western North Atlantic (Perry et al. 1999, Waring et al. 2014). At Cape Hatteras, sperm whale click occurrence peaked during the winter months, when higher concentrations of sperm whales are expected in this region (Perry et al. 1999). Clicks were present at intermediate levels during the spring and early summer, and at consistently low levels during the late summer and fall, when most sperm whales are likely foraging at higher latitudes and in the continental shelf waters off New England (Waring et al. 2014). North of Cape Hatteras, the seasonal peak in sperm whale click occurrence appeared later in the year, with a particularly notable increase during spring at Georges Bank. Wong \& Whitehead (2014) reported a similar higher prevalence of sperm whale clicks during the spring at Kelvin Seamount, part of the New England seamount chain extending southeast from Georges Bank, and it is likely that these seamounts represent an important seasonal foraging habitat for sperm whales. South of Cape Hatteras, seasonal patterns in sperm whale occurrence were 

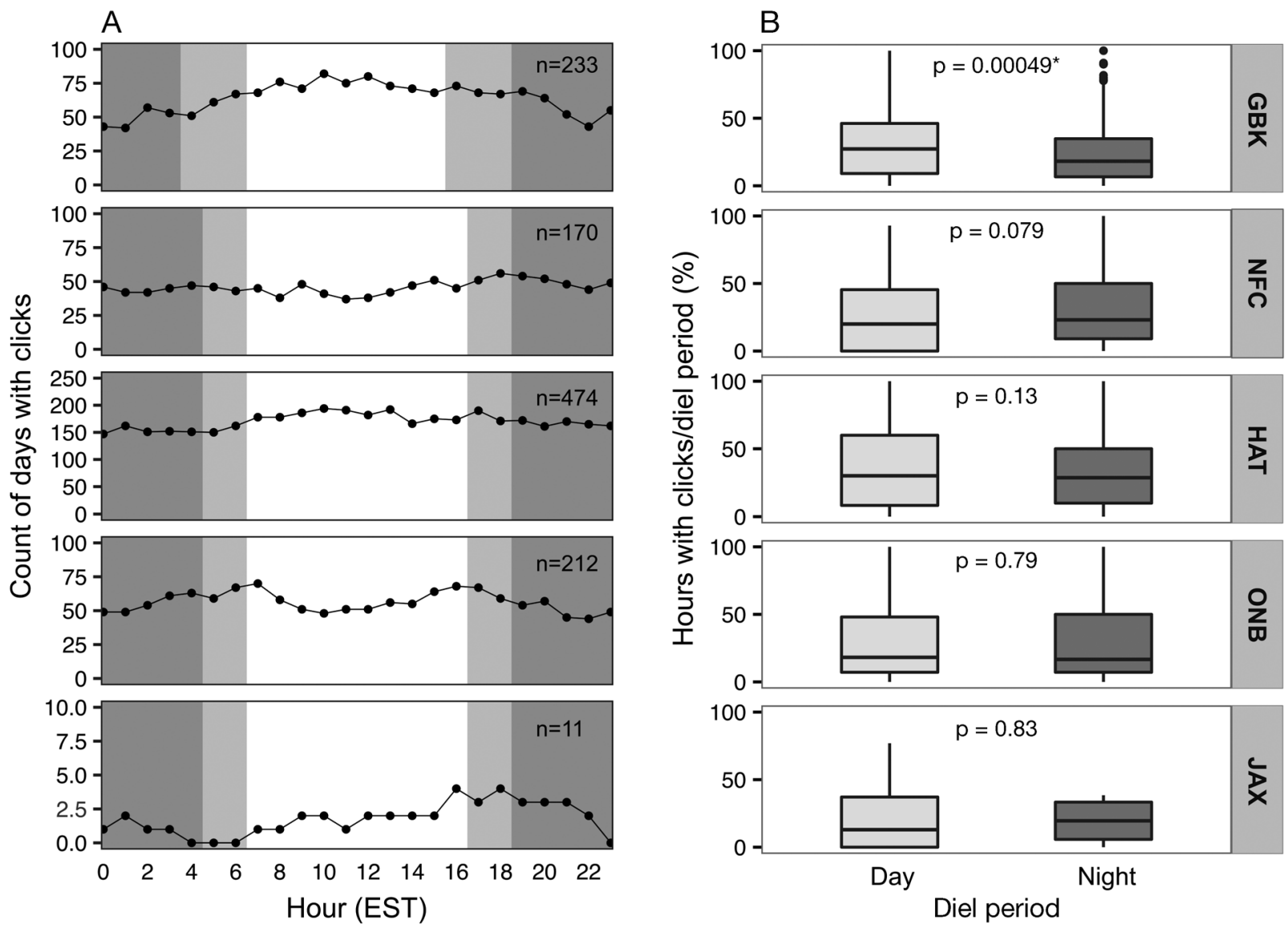

Fig. 5. Diel patterns in sperm whale Physeter macrocephalus click detections across the Georges Bank (GBK), Norfolk Canyon (NFC), Cape Hatteras (HAT), Onslow Bay (ONB), and Jacksonville (JAX) recording sites (applies to panels A and B). (A) Count of the number of days with clicks present in each hour of the day, with dark gray shading indicating nighttime hours, white background indicating daytime hours, and light gray shading indicating hours that were classified as either night or day depending on the time of year. EST: Eastern Standard Time. (B) Percent of hours per diel period with sperm whale clicks, with boxplots showing the median and first and third quartiles, whiskers extending to 1.5 times the inter-quartile range, and points representing data beyond this range. Results of Mann-Whitney $U$ significance tests are $\operatorname{shown}^{*}{ }^{*} \mathrm{p}<0.05$

less apparent in our data, and sperm whale densities may be lower in this region (Roberts et al. 2016b).

The seasonal distribution of sperm whales is likely driven to a large degree by the pursuit of foraging opportunities, which may vary across different spatial and temporal scales (Jaquet \& Whitehead 1996). In the Pacific, sperm whale distributions are broadly associated with regions of higher primary productivity, though these relationships are often difficult to discern due to the spatial and temporal lags between increased primary productivity and enhanced foraging opportunities for upper trophic level predators (Jaquet \& Whitehead 1996, Jaquet et al. 1996). On smaller scales, sperm whales have been found to associate with distinct oceanographic features such as sea-surface temperature fronts (e.g. Gannier \& Praca 2007) and eddies (e.g. Biggs et al. 2000) which may aggregate prey. The prominent oceanographic feature in our study region is the powerful Gulf Stream, flowing north and northeastward just beyond the shelf break. Sperm whales are often encountered near Gulf Stream eddies, particularly where these features interact with bathymetric features of the shelf edge (Waring et al. 1993, Griffin 1999) or seamounts (Wong \& Whitehead 2014). However, these oceanographic relationships are still poorly understood, and knowledge of prey distributions in this region is extremely limited.

The spatial inferences drawn from this study are broad by necessity, because we deployed a single recording device at each site, separated by distances of up to $700 \mathrm{~km}$. Sperm whale distributions are typically patchy, and although the patterns we observed are largely consistent with expected latitudinal trends, they likely reflect characteristics of the individual recording sites as well as broader trends. An 
approximate detection range of $16 \mathrm{~km}$ has been estimated for sperm whale regular clicks at depth (Madsen et al. 2002b), so each of our recording sites should be considered an individual point sample. Detection range may vary due to sound propagation conditions, ambient noise levels, and click characteristics, including source level, directionality, and orientation of the animal relative to the receiver. A full analysis of the site-specific detection ranges and temporal variation in the probability of detecting sperm whale clicks was beyond the scope of this study. Thus, the hourly presence reported here should be considered a minimum estimate of the amount of time one or more sperm whales were present at the location of each recorder. Using hourly time bins reduced some of the variability in click detection because it increased the chances of recording at least a few on-axis clicks over the duration of a foraging dive. Additionally, all recordings were collected at high sampling rates, encompassing the full frequency spectrum of sperm whale clicks. Ambient noise is usually loudest at low frequencies, so the availability of broadband data improved the visibility of clicks.

Our use of GEE-GLM models allowed for a robust comparison of the relative occurrence of sperm whale clicks across seasons, despite the presence of temporal autocorrelation, which reduces the validity of many commonly used statistical tests that rely on the assumption of independence in the response variable. The seasonal comparisons we performed provide a broad overview of seasonality in sperm whale occurrence based on the available recordings, and do not account for temporal variation occurring at finer time scales within seasons. Collecting additional years of recordings, particularly at the Georges Bank and Norfolk Canyon sites, and reducing the gaps between successive deployments would improve our ability to describe and predict seasonal patterns and to detect inter-annual trends in sperm whale occurrence. The use of duty-cycled recording schedules at the Georges Bank and Onslow Bay recording sites likely resulted in some underestimation of hourly presence of sperm whales at these sites, particularly at Georges Bank where data were collected only $10 \%$ of the time (Table 4 ). This reduction in temporal resolution could make seasonal patterns more difficult to detect, but should not create bias in the patterns we observed, because recording effort was consistent across all recording days within a site, and seasonal patterns were modeled separately at each site.

We recorded sperm whale regular clicks across all hours of the day at most recording sites. Although it was not possible to perform a fine-scale analysis of diel patterns on the basis of hourly presence or absence of clicks, we did not observe strong diel patterns in relative presence of sperm whale clicks at any recording site. At Georges Bank, click presence was slightly higher during daylight hours, but the biological significance of this pattern is difficult to discern without further information on the diving behavior and movements of the whales that were present. Diel foraging patterns are common in some odontocete species (e.g. Norris \& Dohl 1980, Carlstrom 2005, Soldevilla et al. 2010), but have been observed inconsistently in sperm whales (e.g. Aoki et al. 2007, Davis et al. 2007), indicating that the foraging behavior of this species may depend on local environmental characteristics and prey behavior. Diel patterns in sperm whale click detections were found in 2 previous passive acoustic monitoring studies conducted within our study region over shorter time periods and at shallower depths. Hodge et al. (2013) observed a clear nocturnal pattern in sperm whale click detections on a recorder deployed near the $200 \mathrm{~m}$ depth contour in Onslow Bay, North Carolina, during summer 2008. Oswald et al. (2016) found a similar pattern on an array of recorders deployed at approximately $180 \mathrm{~m}$ depth in Jacksonville, Florida, during fall 2009. In the present study, we found no evidence of a nocturnal pattern in sperm whale acoustic presence at either the Onslow Bay or Jacksonville recording sites, both of which were located beyond the shelf break at depths greater than $800 \mathrm{~m}$, suggesting that the patterns previously observed at the shallower recording sites may have been a result of the movement of individuals onto the shelf at night.

In addition to foraging opportunities, social factors may play a role in determining the spatiotemporal distribution of sperm whales recorded in this study. Males and females exhibit distinct social behaviors and inhabit different geographic ranges throughout their adult lives. Females and juveniles live in family groups and occupy tropical to temperate waters yearround, while mature males are often solitary and forage at higher latitudes during the summer (Whitehead 2003). Details on the social behavior of sperm whales in the western North Atlantic are scarce, but it is likely that we recorded groups of females and calves as well as solitary males in this study, because their estimated ranges overlap throughout our study region (Perry et al. 1999). Lone individuals and groups of sperm whales with calves have been observed during shipboard and aerial surveys conducted along the continental shelf break and slope in 
southern New England and off the Mid-Atlantic coast (data not shown).

Quantifying the occurrence of different sperm whale click types could provide some insight into the demographics and social context of animals present. Slow clicks are produced only by mature males (Weilgart \& Whitehead 1988), while codas are most frequently recorded among female groups (Whitehead \& Weilgart 1991, Marcoux et al. 2006), and coda types can provide information on social organization, such as to which acoustic clan the individuals belong (Rendell \& Whitehead 2003, Gero et al. 2016). Here, we did not analyze the recordings for slow clicks and codas, because these click types were difficult to visually distinguish in the LTSAs, due to their energy content at lower frequencies which coincided with higher levels of ambient noise, and to the lower source levels of coda clicks (Madsen et al. 2002a). A thorough analysis of these click types would require a detailed manual examination of the recordings using spectrograms, which was not feasible with the $5.5 \mathrm{yr}$ of data collected in this study. Furthermore, codas are most often recorded when animals are observed socializing near the surface rather than during deep dives (Whitehead \& Weilgart 1991), and it is not known how well these signals propagate to bottom-mounted recorders deployed in deep water. Investigating the detectability of codas on hydrophones located at depth and developing efficient methods to detect and classify sperm whale codas and slow clicks within large acoustic datasets would be useful objectives for future studies.

In this paper, we have demonstrated the use of broad-scale passive acoustic monitoring to assess spatial and temporal patterns in sperm whale occurrence. The spatiotemporal distribution of sperm whales in the western North Atlantic and elsewhere around the world has been shaped in significant and complex ways by the long history of human exploitation of the species, which dramatically reduced their populations. To date, there is little evidence that sperm whale populations have recovered since the cessation of large-scale commercial whaling more than 30 yr ago (Carroll et al. 2014, Gero \& Whitehead 2016), and the species is internationally listed as Vulnerable on the IUCN Red List of Threatened Species. Understanding the contemporary seasonal distribution of sperm whales has important implications for management and conservation, as they still face a wide range of human-caused stressors, including entanglement in fishing gear, ship strikes, and exposure to anthropogenic noise (e.g. Laist et al. 2001, Moore \& van der Hoop 2012, Isojunno et al. 2016).
Passive acoustic monitoring is a valuable non-invasive tool for obtaining consistent year-round information on sperm whale occurrence and gaining insight into seasonal movement patterns. Our results provide a comprehensive year-round baseline on the occurrence of this species at multiple recording sites in the western North Atlantic Ocean, and suggest a seasonal shift in sperm whale occurrence particularly north of Cape Hatteras. To improve the utility of these results, we recommend continued passive acoustic monitoring across multiple years at the same study sites, with an effort to minimize the gaps in recording time between successive instrument deployments. Additionally, the integration of seasonal occurrence data obtained from passive acoustic monitoring with broader spatial data collected through visual surveys as well as fine-scale behavioral data will help to create a richer understanding of the ecology of sperm whales.

Acknowledgements. We sincerely thank T. Boynton, Z. Swaim, J. Dunn, H. Foley, R. Griswold, J. Hurwitz, E. O'Neill, B. Thayre, and S. Wiggins for logistical support and field assistance with HARP deployments and data processing. We thank A. DeAngeles, J. Prezioso and the crew of the NOAA ship 'Henry Bigelow' for their assistance with the AMAR deployment and recovery, and B. Martin, C. Whitt and JASCO Applied Sciences for AMAR support and data processing. Funding for HARP data collection was provided by US Fleet Forces Command with technical support from Naval Facilities Engineering Command Atlantic. Funding for AMAR data collection was provided by the US Navy's N45 Environmental Readiness Division. J.E.S. was supported in part by a National Defense Science and Engineering Graduate Fellowship.

\section{LITERATURE CITED}

Aoki K, Amano M, Yoshioka M, Mori K, Tokuda D, Miyazaki N (2007) Diel diving behavior of sperm whales off Japan. Mar Ecol Prog Ser 349:277-287

Backus RH, Schevill WE (1966) Physeter clicks. In: Norris KS (ed) Whales, dolphins and porpoises. University of California Press, Berkeley, CA, p 510-527

Bailey H, Corkrey R, Cheney B, Thompson PM (2013) Analyzing temporally correlated dolphin sightings data using generalized estimating equations. Mar Mamm Sci 29:123-141

* Barlow J, Taylor BL (2005) Estimates of sperm whale abundance in the northeastern temperate Pacific from a combined acoustic and visual survey. Mar Mamm Sci 21: 429-445

Baumann-Pickering S, Roch MA, Brownell RL Jr, Simonis AE and others (2014) Spatio-temporal patterns of beaked whale echolocation signals in the North Pacific. PLOS ONE 9:e86072

Best PB (1983) Sperm whale stock assessments and the relevance of historical whaling records. Rep Int Whal Comm Spec Issue 5:41-55 
Biggs DC, Leben RR, Ortega-Ortiz JG (2000) Ship and satellite studies of mesoscale circulation and sperm whale habitats in the northeast Gulf of Mexico during GulfCet II. Gulf Mex Sci 1:15-22

Carlstrom J (2005) Diel variation in echolocation behavior of wild harbor porpoises. Mar Mamm Sci 21:1-12

Carroll G, Hedley S, Bannister J, Ensor P, Harcourt R (2014) No evidence for recovery in the population of sperm whale bulls off Western Australia, 30 years post-whaling. Endang Species Res 24:33-43

Davis RW, Jaquet N, Gendron D, Markaida U, Bazzino G, Gilly W (2007) Diving behavior of sperm whales in relation to behavior of a major prey species, the jumbo squid, in the Gulf of California, Mexico. Mar Ecol Prog Ser 333: 291-302

Gannier A, Praca E (2007) SST fronts and the summer sperm whale distribution in the north-west Mediterranean Sea. J Mar Biol Assoc UK 87:187-193

Gero S, Whitehead H (2016) Critical decline of the Eastern Caribbean sperm whale population. PLOS ONE 11: e0162019

* Gero S, Bøttcher A, Whitehead H, Madsen PT (2016) Socially segregated, sympatric sperm whale clans in the Atlantic Ocean. R Soc Open Sci 3:160061

Goode GB (1884) The fisheries and fishery industries of the United States. Government Printing Office, Washington, DC

* Griffin RB (1999) Sperm whale distributions and community ecology associated with a warm-core ring off Georges Bank. Mar Mamm Sci 15:33-51

Halekoh U, Højsgaard S, Yan J (2006) The R package geepack for generalized estimating equations. J Stat Softw 15:1-11

Hodge LEW, Bell JT, Kumar A, Read AJ (2013) The influence of habitat and time of day on the occurrence of odontocete vocalizations in Onslow Bay, North Carolina. Mar Mamm Sci 29:E411-E427

" Isojunno S, Curé C, Kvadsheim PH, Lam FPA, Tyack PL, Wensveen PJ, Miller PJOM (2016) Sperm whales reduce foraging effort during exposure to $1-2 \mathrm{kHz}$ sonar and killer whale sounds. Ecol Appl 26:77-93

* Jaquet N, Whitehead H (1996) Scale-dependent correlation of sperm whale distribution with environmental features and productivity in the South Pacific. Mar Ecol Prog Ser 135:1-9

Jaquet N, Whitehead H, Lewis M (1996) Coherence between 19th century sperm whale distributions and satellite-derived pigments in the tropical Pacific. Mar Ecol Prog Ser 145:1-10

* Laist DW, Knowlton AR, Mead JG, Collet AS, Podestà M (2001) Collisions between ships and whales. Mar Mamm Sci 17:35-75

Lenth RV (2016) Least-squares means: the R package lsmeans. J Stat Softw 69:1-33

* Liang KY, Zeger SL (1986) Longitudinal data analysis using generalized linear models. Biometrika 73:13-22

Madsen PT, Payne R, Kristiansen NU, Wahlberg M, Kerr I, Møhl B (2002a) Sperm whale sound production studied with ultrasound time/depth-recording tags. J Exp Biol 205:1899-1906

Kadsen PT, Wahlberg M, Møhl B (2002b) Male sperm whale (Physeter macrocephalus) acoustics in a high-latitude habitat: implications for echolocation and communication. Behav Ecol Sociobiol 53:31-41

Marcoux M, Whitehead H, Rendell L (2006) Coda vocali- zations recorded in breeding areas are almost entirely produced by mature female sperm whales (Physeter macrocephalus). Can J Zool 84:609-614

* Mellinger DK, Stafford KM, Fox CG (2004) Seasonal occurrence of sperm whale (Physeter macrocephalus) sounds in the Gulf of Alaska, 1999-2001. Mar Mamm Sci 20: 48-62

Miller PJO, Johnson MP, Tyack PL (2004) Sperm whale behaviour indicates the use of echolocation click buzzes 'creaks' in prey capture. Proc R Soc B 271:2239-2247

Møhl B, Wahlberg M, Madsen PT, Heerfordt A, Lund A (2003) The monopulsed nature of sperm whale clicks. J Acoust Soc Am 114:1143-1154

Moore MJ, van der Hoop JM (2012) The painful side of trap and fixed net fisheries: chronic entanglement of large whales. J Mar Biol 2012:1-4

Norris KS, Dohl TP (1980) Behavior of the Hawaiian spinner dolphin, Stenella longirostris. Fish Bull 77:821-849

Oswald JN, Norris TF, Yack TM, Ferguson EL, Kumar A, Nissen J, Bell J (2016) Patterns of occurrence and marine mammal acoustic behavior in relation to Navy sonar activity off Jacksonville, Florida. In: Popper AN, Hawkins A (eds) The effects of noise on aquatic life. II. Advances in Experimental Medicine and Biology 875. Springer, New York, NY, p 791-799

* Panigada S, Zanardelli M, MacKenzie M, Donovan C, Mélin F, Hammond PS (2008) Modelling habitat preferences for fin whales and striped dolphins in the Pelagos Sanctuary (Western Mediterranean Sea) with physiographic and remote sensing variables. Remote Sens Environ 112: 3400-3412

Perry SL, DeMaster DP, Silber GK (1999) The Sperm whale. Mar Fish Rev 61:59-74

* Pirotta E, Thompson PM, Miller PI, Brookes KL and others (2014) Scale-dependent foraging ecology of a marine top predator modelled using passive acoustic data. Funct Ecol 28:206-217

Rendell LE, Whitehead H (2003) Vocal clans in sperm whales (Physeter macrocephalus). Proc R Soc B 270: 225-231

Rice DW (1989) Sperm whale, Physeter macrocephalus Linnaeus, 1758. In: Ridgeway SH, Harrison R (eds) Handbook of marine mammals, Vol. 4: River dolphins and the larger toothed whales. Academic Press, New York, NY, p 177-233

Risch D, Castellote M, Clark CW, Davis GE and others (2014) Seasonal migrations of North Atlantic minke whales: novel insights from large-scale passive acoustic monitoring networks. Mov Ecol 2:24

* Roberts JJ, Best BD, Mannocci L, Fujioka E and others (2016a) Habitat-based cetacean density models for the U.S. Atlantic and Gulf of Mexico. Sci Rep 6:22615

Roberts JJ, Best BD, Mannocci L, Fujioka E and others (2016b) Density model for sperm whale (Physeter macrocephalus) for the U.S. East Coast Version 6.4, 2016-04-21, and Supplementary Report. Marine Geospatial Ecology Lab, Duke University, Durham, NC

Smith TD, Reeves RR, Josephson EA, Lund JN (2012) Spatial and seasonal distribution of American whaling and whales in the age of sail. PLOS ONE 7:e34905

K Soldevilla MS, Wiggins SM, Hildebrand JA (2010) Spatial and temporal patterns of Risso's dolphin echolocation in the Southern California Bight. J Acoust Soc Am 127: 124-132

Thomisch K, Boebel O, Clark CW, Hagen W, Spiesecke S, 
Zitterbart DP, Van Opzeeland I (2016) Spatio-temporal patterns in acoustic presence and distribution of Antarctic blue whales Balaenoptera musculus intermedia in the Weddell Sea. Endang Species Res 30:239-253

Tomilin AG (1957) Mammals of the U.S.S.R. and adjacent countries, Vol. IX: Cetacea. In: Heptner VG (ed) Mammals of the U.S.S.R. and adjacent countries, Vol. IX: Cetacea. Nauk SSSR, Moscow, p 329-383 (in Russian, English translation 1967 by Israel Program for Scientific Translation, Jerusalem, US Department of Commerce, Springfield, VA)

Townsend $\mathrm{CH}$ (1935) The distribution of certain whales as shown by logbook records of American whaleships. Zoologica (NY) 19:1-50

Wahlberg M (2002) The acoustic behaviour of diving sperm whales observed with a hydrophone array. J Exp Mar Biol Ecol 281:53-62

Waring GT, Fairfield CP, Ruhsam CM, Sano M (1993) Sperm whales associated with Gulf Stream features off the north-eastern USA shelf. Fish Oceanogr 2:101-105

Waring GT, Hamazaki T, Sheehan D, Wood G, Baker S (2001) Characterization of beaked whale (Ziphiidae) and sperm whale (Physeter macrocephalus) summer habitat in shelf-edge and deeper waters off the northeast U.S. Mar Mamm Sci 17:703-717

Waring GT, Josephson E, Maze-Foley K, Rosel PE (eds) (2014) U.S. Atlantic and Gulf of Mexico Marine Mammal Stock Assessments - 2013. NOAA Tech Memo NMFS NE 228

Watkins WA, Schevill WE (1977) Sperm whale codas. J Acoust Soc Am 62:1485-1490

Editorial responsibility: Mike Noad, Gatton, Queensland, Australia
Watwood SL, Miller PJO, Johnson M, Madsen PT, Tyack PL (2006) Deep-diving foraging behaviour of sperm whales (Physeter macrocephalus). J Anim Ecol 75:814-825

* Weilgart L, Whitehead H (1988) Distinctive vocalizations from mature male sperm whales (Physeter macrocephalus). Can J Zool 66:1931-1937

* Weilgart L, Whitehead H (1993) Coda communication by sperm whales (Physeter macrocephalus) off the Galapagos Islands. Can J Zool 71:744-752

Whitehead H (2002) Estimates of the current global population size and historical trajectory for sperm whales. Mar Ecol Prog Ser 242:295-304

Whitehead H (2003) Sperm whales: social evolution in the ocean. University of Chicago Press, Chicago, IL

Whitehead H, Weilgart L (1991) Patterns of visually observable behaviour and vocalizations in groups of female sperm whales. Behaviour 118:275-296

Wiggins SM, Hildebrand JA (2007) High-frequency Acoustic Recording Package (HARP) for broad-band, longterm marine mammal monitoring. Symposium on Underwater Technology and Workshop on Scientific Use of Submarine Cables and Related Technologies, Tokyo, 17 20 Apr 2007, p 551-557

Wong SNP, Whitehead H (2014) Seasonal occurrence of sperm whales (Physeter macrocephalus) around Kelvin Seamount in the Sargasso Sea in relation to oceanographic processes. Deep Sea Res I 91:10-16

Zimmer WMX, Madsen PT, Teloni V, Johnson MP, Tyack PL (2005) Off-axis effects on the multipulse structure of sperm whale usual clicks with implications for sound production. J Acoust Soc Am 118:3337-3345

Submitted: February 10, 2017; Accepted: October 6, 2017 Proofs received from author(s): December 16, 2017 